\title{
Trends in Gerontology
}

\author{
By WILLIAM B. KOUNTZ, M.D.
}

$\mathrm{W}$

HAT IS GERONTOLOGY? We might say that it is an understanding of the process of aging, or a form of therapy, or a form of evaluation of the problem of aging. All these are true in their own way, but, actually, gerontology is a cumulative process of thinking in regard to one of the important problems of existence. Gerontology is indeed a broad word, covering many facets of our existence.

Much like medicine itself, gerontology had to create a logical place in the human mind before it could be established. Since thought develops slowly and in stages, the most critical point is usually the one considered first by the mind. Because of the need, generations ago, for attention to the health of the younger individual, the problems of the early years of life were attacked most vigorously and the science of pediatrics was established. It was only after the application of this direction of study and observation of the results that the problems of the period past midlife became critical in the mind of man. We are now at the stage where gerontological control in all its different phases and aspects looms high as one of the greatest needs of mankind.

Since gerontology is divided into different units, or disciplines, we shall consider each one separately.

Dr. Kountz is assistant professor of clinical medicine, Washington University School of Medicine, St. Louis, Mo.

\section{Biology}

Since there is definite biological change in everyone from his unicellular state to maturity, the biological problem is important not only in the period of growth and development, but also in maturity and later years. In considering the biological aspect of aging, there are a number of questions that must be asked: Is the body as it ages fixed in its principle so that the changes cannot be modified? Should we expect biological change to be comparable to the process of boiling an egg? Can such anatomical and functional changes as occur with age be modified?

These questions have been answered definitely. It has been shown that there may be a reversal in the picture of tissue, both biologically and functionally, long after the tissue has ceased its normal activity, that actually the functional capacity of the tissue may be returned to near normal and the biological appearance of the cells and tissues may again approach that of younger periods of life. Since this can be demonstrated in certain tissues, it is highly possible that other tissues may be modified in both their functional capacities and anatomical appearance.

It has been shown that the epithelium of the nose and throat may again develop cilia and that an improvement of this tissue may occur after the functional capacity of the mechanism has been greatly reduced. It has been demonstrated that the endometrium of the uterus may be returned to a state resembling its former state in anatomical appearance and even, in part, in function. With proper therapy, the 
blood ressels of the uterus may even tend to lose their calcification, which was due to arterial strain. It has been demonstrated that the mental response of a patient may be improved, that such things as memory, ability to coordinate thought, judgment, and the like, may be benefited by therapy. We can say that the biological function and physical tissue may be modified and that they parallel one another. This phase of gerontology needs much research, and much may be accomplished by proper study and evaluation.

Can and should these changes be modified? From my limited experience I feel that knowledge will lead to a definite modification of tissue and its function, which will in turn extend the health of older people. Many of the diseases found in older people are attributed to arteriosclerosis, but since the advent of pathology physicians have found that a clinical diagnosis of arteriosclerosis is not always substantiated by autopsy findings. Children died of diarrhea, which was later found to be preventable by control of the nutritional state of the infant. The trend in biological study is upward, but the ascent is very slow.

\section{Psychology}

There are so many factors that influence the psychology of the older person that it is difficult to evaluate them briefly. The need for a better adjustment of the older person to his environment, the need for economic, social, and medical security, all enter into the mental and emotional disturbance of his existence. Control of these factors leads to a healthier outlook on life, to a better understanding of the emotions, and must come through proper education of the individual and a realization on his part that aging is not something to be shunned, but something to be accepted and adjusted to. As most of our youngsters are taught, so should our oldsters be taught that they must prepare themselves for the future in order to have a pleasant corner in life at any age.

There is an increasing realization of the need to develop this thought. I can point particularly to the University of Michigan, which has taken the lead in the control of the psychological aspect of older people. This institution is well known for studies concerning the mental health, the emotional needs, the adjustment to an industrial program, and the education of the older person. Proper thinking in the field of psychology of the aging by the leaders is well assured. Administration of this thought to those who need it is, of course, difficult. It must come with education of the masses of older people. The trend toward proper evaluation in the field of psychology is strong.

\section{Clinical Medicine}

Clinical medicine has for generations shied away from the subject of gerontology and is still doing so. Few medical schools teach any of its principles. Few of the teachers in the schools realize its importance, and consequently few teach medical students and interns the problems of aging, particularly the anticipation of disease. They sack up most diseases that occur in older people and call them arteriosclerosis and shake their heads and say: It is inevitable. There is an awakening of thought in the direction that some of the changes that occur with age may be modified and that basic underlying changes which lead to the diseases of the older person may be recognized and treated. However, the problems of geriatric medicine have not yet received proper recognition.

The trend in clinical medicine is a sort of status quo. Many clinicians still think that illness must occur with age. Since they feel that a disease must occur before treatment is started, they are unable to approach the prophylaxis of gerontology. They are unwilling to anticipate that illness may occur unless something is done to direct and control the body functions. It is important to emphasize that acute phases of chronic disease do not occur suddenly; rather they progress slowly and have their existence as a result of changes that began long before the acute phases developed. Internal medicine needs to take a page out of the book of pediatrics from the standpoint of prophylactic and anticipatory medicine.

Nevertheless, the clinical state of the older patient has been much improved. Many types of conditions that frequently lead to chronic diseases are now controllable. For instance, 
hypertension, or high blood pressure, has been brought under control to a great extent in the past few years, a fact that will doubtless help to prevent illness in many oldsters. The understanding of dietary problems, such as the influence of fats in the control of arterial disease, and the understanding of the nutrition of the body likewise play an important part in the control of chronic disease. Surgery, with its ability to replace diseased blood vessels, leads to improved health in the older person. The early recognition and surgical treatment of cancer of the breast, the uterus, and the lung also help to extend health into the later years of life. And much could be said about the introduction of medications and techniques in specific disease, all of which lead to better health.

The trend in the clinical aspect of the control of disease in older people is definitely upward, but there is still need for earlier recognition and earlier clinical evaluation before prevention of disease can come into its own. The treatment and control of disease in older people has been much improved, and the trend to better health is a trend to a brighter outlook.

\section{Other Aspects}

The social, economic, and religious aspects of life for older persons vary a great deal from these aspects of life for young people. The social aspect is often modified by a change in clinical health, in economic ability, and particularly in the psychological outlook of older individuals. That social needs should be recognized and social adjustment aided there can be no doubt. The trend is in this direction: for example, social security, old age pensions, and housing projects for the aged. Fraternal organizations and other groups are beginning to make moves toward meeting the needs of their retired members. In my experience the social aspect is always conditioned by psychological and clinical health. Those in poor health need social adjustment and social help; those in good health maintain their own level.

Another trend of great importance is the increasing concern among lay people with the results of gerontological research. If properly directed, their interest can speed the progress of gerontology. It will serve to create a demand on scientists and physicians to develop the knowledge necessary to assure health in the later years. This emphasizes the need for the formation of foundations to help develop further study and to establish funds for research, as well as to permit the expression of lay people in the field. This type of organization enables the layman and the scientist to become partners in gerontological research, and no more important a relationship can be established. One such organization, the Gerontological Research Foundation, has already been set up.

\section{Directs Program on Aging}

William C. Fitch, of the Bureau of Old-Age and Survivors Insurance, has been named director of the special staff on aging, a newly created post in the Department of Health, Education, and Welfare.

Mr. Fitch, who began his career in 1937 as assistant manager of the Kingston, N. Y., Social Security District Office, was assistant to the director of the Bureau of Old-Age and Survivors Insurance prior to this appointment. He was a member of the Department's Committee on Aging and consultant to two of the annual University of Michigan conferences on aging. In September 1956 he returned to the United States after serving for a year as social insurance adviser to the Government of Israel.

The special staff on aging represents an expansion of the Department's program on aging. Clark Tibbitts will continue as chairman of the Department's Committee on Aging, established in 1950. 